\title{
Immune function as predictor of infectious complications and clinical outcome in patients undergoing solid organ transplantation (the ImmuneMo:SOT study): a prospective non-interventional observational trial
}

\author{
Camilla Heldbjerg Drabe ${ }^{1}$, Søren Schwartz Sørensen ${ }^{2}$, Allan Rasmussen ${ }^{3}$, Michael Perch $^{4}$, Finn Gustafsson ${ }^{5}$, \\ Omid Rezahosseini ${ }^{1}$, Jens D. Lundgren ${ }^{6}$, Sisse Rye Ostrowski ${ }^{7}$ and Susanne Dam Nielsen ${ }^{1 *}$ (id
}

\begin{abstract}
Background: Solid organ transplantation (SOT) is a well-established and life-saving treatment for patients with endstage organ failure. Organ rejection and infections are among the main complications to SOT and largely determines the clinical outcome. The correct level of immunosuppression is of major importance to prevent these complications. However, it is a consistent observation that in recipients on the same immunosuppressive regimens the clinical outcome varies, and no reliable marker exists to monitor immune function.

Methods: In a prospective, observational study, we plan to enroll 630 adult patients with a planned organ transplantation at Rigshospitalet, University of Copenhagen, Denmark. Prior to and on different time points up to two years after transplantation we will perform a complete immunological profile on the recipients. This profile will consist of classical descriptive immune phenotyping (flow cytometry and circulating biomarkers) and the functional assay TruCulture ${ }^{\oplus}$. In TruCulture ${ }^{\oplus}$ whole blood is incubated ex vivo with stimulants imitating bacterial, viral and fungal infections, where after a panel of selected cytokines is quantified. Clinical data from electronic health records will be obtained from the PERSIMUNE (Centre of Excellence for Personalized Medicine of Infections Complications in Immune Deficiency at Rigshospitalet, Copenhagen) data repository, a warehouse of data generated as part of routine care including vital signs, biochemistry, microbiology, pathology as well as medication, demographics, diagnoses, hospital contacts, surgical procedures and mortality.

Discussion: This will be the first large scale study to determine several aspects of immune function and perform a complete immunological profiling in SOT recipients. It is expected that knowledge generated will provide information to generate prediction models identifying patients at increased risk of infection and/or rejection. If the study is successful, we will subsequently use the generated prediction models to propose personalized immunosuppressive regimens to be tested in future randomized controlled trials.
\end{abstract}

Trial registration: This study has been approved by the Regional ethical committee ( $\mathrm{H}-17024315)$, the Danish Data Protection Agency (RH-2016-47, RH-2015-04, I-Suite 03605) and the Danish National board of Health (3-3013-1060/1). The trial is retrospectively registered at clinicaltrials.gov (NCT03847285) the 20th February 2019.

Keywords: Immunomodulation, Organ transplantation, Immunosuppression, Infection, Graft rejection, Precision medicine

\footnotetext{
* Correspondence: sdn@dadlnet.dk

${ }^{1}$ Viro-immunology Research Unit, Department of Infectious Diseases,

Rigshospitalet, University of Copenhagen, Copenhagen, Denmark

Full list of author information is available at the end of the article
}

(c) The Author(s). 2019 Open Access This article is distributed under the terms of the Creative Commons Attribution 4.0 International License (http://creativecommons.org/licenses/by/4.0/), which permits unrestricted use, distribution, and reproduction in any medium, provided you give appropriate credit to the original author(s) and the source, provide a link to the Creative Commons license, and indicate if changes were made. The Creative Commons Public Domain Dedication waiver (http://creativecommons.org/publicdomain/zero/1.0/) applies to the data made available in this article, unless otherwise stated. 


\section{Background}

Solid organ transplantation (SOT) is an wellestablished and life-saving treatment for patients with organ failure $[1,2]$. Immunosuppressive drugs are required to prevent graft rejection but increases the risk of infections. Infectious complications are a leading cause of morbidity and mortality after SOT [3]. Pathogens and clinical presentations vary with type of transplanted organ, immunosuppressive regimens and infection-prophylaxis strategies. The most common infections are bacterial and viral, and the incidence of bacterial infections has been reported up to 30-68\% per year in SOT recipients [4]. Acute rejection is reported in $27-46 \%$ of liver transplant recipients [5], $24 \%$ of kidney transplant recipients [6], 60\% of lung transplant recipients [7] and in 56\% of heart transplant recipients [8].

At present, immunosuppressive drugs are dosed according to weight and monitored by drug concentrations, and no reliable biomarker is available to guide dosing. In SOT recipients on the same immune suppression, some will develop severe infections or graft rejection, whereas others experience a good clinical outcome [1], indicating that the function of the immune system may contribute to the observed variation. Multiple studies have suggested that cytokines or specific cell populations may be biomarkers for SOT outcome, but so far no reliable marker has been identified (reviewed by Dendle et al. [9]).

The use of functional assays to determine immune function has gained attention as a possible tool to improve dosage of immunosuppression in SOT recipients [10-23]. Previously, functional assays have been expensive and required high level of technical skills and hands-on time in the laboratory, limiting the utility of this approach. However, recently commercially available functional assays such as the ImmuKnow ${ }^{\oplus}$, QuantiFERON-monitor $^{\odot}$ and TruCulture ${ }^{\odot}$ have become available, and large-scale functional assays are now feasible. Promising results were reported by Mian et al., who found that a low whole blood response of interferon gamma (INF- $\gamma$ ) after overnight stimulation with anti-CD3 (T-cell stimulant) and R848 (a Toll-like receptor 7 ligand), was associated with subsequent infections in SOT recipients [10], and Ravaioli et al. have found that immunosuppressive dosage according to results of ImmuKnow ${ }^{\circledR}$ improved the clinical outcome for liver transplant recipients [11].

There is an urgent need for improved understanding of the immunopathology contributing to risk of infections and rejections in SOT recipients. An improved understanding of the immune-pathophysiology combined with development of new immunologic diagnostic tools may promote a shift from empirical treatment to precision-guided care tailored to each patient, with expected improved patient outcomes.

In this "immune function as predictor of infectious complications and clinical outcome in patients undergoing solid organ transplantation (The ImmuneMo:SOT study)" study, we will examine SOT-recipients (prior to and after transplantation) with a complete immunologic profiling consisting of immune phenotype (high-dimensional flow cytometri), circulating biomarkers and the novel functional immune assay TruCulture ${ }^{\circledR}$. The study is developed in collaboration with experts in infectious diseases, immunology and clinicians taking care of SOT recipients at Rigshospitalet, MATCH (Management of Post-Transplant Infections in Collaborating Hospitals, Rigshospitalet, Copenhagen, Denmark), PERSIMUNE (Centre of Excellence for Personalized Medicine of Infections Complications in Immune Deficiency at Rigshospitalet, Copenhagen, Denmark) and Milieu Intérieur, Institute Pasteur, Paris, France. It will be the first large scale study to determine multiple aspects of immune function and perform a complete immunological profiling in SOT recipients. We aim to 1) determine the combined effect of organ transplantation and immunosuppressive drugs on immune function, 2) determine if immune function profiling/monitoring can be used to predict infections and rejections, and 3) design a prediction a model to identify patients with the highest risk of infections. If the study is successful, these prediction models will be used to generate a treatment program using personalized medicine based on immune function that will be tested in randomized clinical trials.

\section{Methods/design}

This ImmuneMo:SOT study is a non-interventional, observational study. It was initiated in February 2018 and inclusion will continue until March 2021.

\section{Study-participants}

To be eligible for the study the participant must be a minimum of 18 years of age and have a planned kidney-, heart-, lung-, liver- or pancreas-transplant and be able to provide informed consent. Study participation is strictly voluntary.

During a three-year-period we aim to include 630 SOT recipients: $n=270$ kidney-, $n=90$ lung-, $n=45$ heart-, $n=180$ liver-, and $n=45$ pancreas recipients from Rigshospitalet, University of Copenhagen [1]. A study nurse is employed to ensure adequate participant enrolment and complete follow-up.

\section{Complete immunological profile}

In all participants we will collect blood samples before the transplantation (either while the patient is on waiting list or just before the surgical procedure and before the 
initiation of immunosuppression) and 7-14 days, 3 months, 6 months, 12 months and 24 months posttransplantation.

The complete immunologic profiling includes concomitant characterization of immune phenotypes and circulating plasma biomarkers and determination of immune function (Table 1). This immunologic profile is developed in collaboration with experts in infectious diseases, immunology and clinicians taking care of SOT recipients at Rigshospitalet, PERSIMUNE, MATCH and Milieu Intérieur, Institute Pasteur, Paris, France, the latter taking advantage of their experience with immunologic profiling in The Healthy Human Global Project [24-29].

\section{Immune phenotype}

Immune phenotyping will be conducted in a subset of participants $(N=100-630$ depending on funding). The flow cytometry panel will be designed to reveal the immune phenotypes of critical developmental and/or activation stages of immune cells to capture deviated maturation patterns, acute/chronic activation, exhaustion, migration/trafficking potential and deviated expression of immune checkpoint markers.

\section{Circulating plasma biomarkers}

Circulating levels of cytokines will be measured in a subset of participants $(N=100-630$ depending on funding). The panel will include immune or inflammatory cytokines, autoantibodies against cytokines, chemokines, growth factors, adhesion molecules that injury/death products reflecting the magnitude of immune cell- and/ or tissue activation and/or injury in vivo will be assessed by measuring the biomarkers. The soluble plasma biomarkers as well as autoantibodies against these will be measured by high-throughput multiplex platforms like Luminex ${ }^{\circ}$ or Meso Scale Discovery $\left(\mathrm{MSD}^{\circ}\right)$, by NanoString $^{\odot}$ and by enzyme linked immunosorbent assay (ELISA).

\section{Immune function}

To provide a standardized and robust analysis, immune function is assessed by the commercially available test TruCulture $^{\bullet}$ (Myriad RBM, Austin, USA). TruCulture ${ }^{\bullet}$ reproducibly reveals the induced innate and adaptive immune response in whole blood after stimulation, by quantifying the release of soluble immune activation products (cytokines, chemokines, soluble receptors etc.) in the supernatant and by measuring the transcription level (mRNA) in the circulating blood (immune) cells $[24,30]$.

We have chosen four different stimuli, mimicking the presence of fungal, bacterial and two different viral agents, to obtain a broad function of different immunologic signaling pathways, including Toll Like Receptors (TLR) (Table 2). The four stimuli consists of heat killed Candida albicans (HKCA), bacterial endotoxin (lipopolysaccharide (LPS) from Escherichia coli (E.coli)), resiquimod R848 and polyinosinic:polycytodylic acid (poly I: C). Every tube holds one stimulus. HKCA is a whole microbe that provides a complex immunological stimulation including stimulation through TLR6. HKCA mimics

Table 1 Method and data output of the immunological profile. Description of blood sample collection, laboratory analysis and dataoutput from the immunological profile, consisting of immune phenotype (flow cytometry), immune function (TruCulture ${ }^{\oplus}$ ) and circulating plasma biomarkers

\begin{tabular}{|c|c|c|}
\hline & Method & Data output \\
\hline Immune phenotype (flow cytometry) & $\begin{array}{l}3 \mathrm{ml} \text { EDTA anticoagulated whole blood. The whole } \\
\text { blood is analyzed on a Navios flow cytometer } \\
\text { (Beckman-Coulter) within } 24 \mathrm{~h} \text { after blood sampling. }\end{array}$ & $\begin{array}{l}\text { Proportion and intensity (mean fluorescence } \\
\text { intensity, MFI) of antigens (most designated } \\
\text { clusters of differentiation, CD) on the blood } \\
\text { immune cells investigated in the flow } \\
\text { cytometry panel. }\end{array}$ \\
\hline Immune function (TruCulture ${ }^{\circledast}$ ) & $\begin{array}{l}9 \mathrm{ml} \text { lithium heparin anticoagulated whole blood. } \\
\text { The whole blood is transferred to individual } \\
\text { TruCulture }{ }^{\circledR} \text { tubes } 60 \text { min after blood sampling. } \\
\text { After } 22 \mathrm{~h} \text { incubation at } 37^{\circ} \mathrm{C} \text {, the TruCulture } \\
\text { supernatant is harvested and aliquoted to cryo } \\
\text { tubes and frozen at }-20^{\circ} \mathrm{C} \text { for later thawing and } \\
\text { bulk analysis of soluble immune activation products. } \\
\text { The mRNA in the TruCulture }{ }^{\circledR} \text { cell pellet is stabilized } \\
\text { by Trizol and frozen at }-80^{\circ} \mathrm{C} \text { for later bulk analysis } \\
\text { of mRNA expression level of stimulated immune } \\
\text { proteins. }\end{array}$ & $\begin{array}{l}\text { TNF- } a \text {, IL-1 } \beta, I L-6, I L-8 / C X C L 8, I L-10, I L-12 p 40 \text {, } \\
\text { IL-17A, IFN- } \gamma \\
\text { Expression levels of the immune protein mRNA } \\
\text { included in the multiplex assay will be calculated } \\
\text { and reported. }\end{array}$ \\
\hline Circulating plasma biomarkers & $\begin{array}{l}6 \mathrm{ml} \text { EDTA and } 3.5 \mathrm{ml} \text { sodium citrate } 3.2 \% \\
\text { anticoagulated whole blood. The whole blood is } \\
\text { spun ( } 3000 \mathrm{RPM}, 10 \mathrm{~min} \text { ) within maximum } 6 \mathrm{~h} \text { after } \\
\text { blood sampling and plasma is aliquoted into cryo } \\
\text { tubes and frozen at }-20^{\circ} \mathrm{C} \text {, and later transferred } \\
\text { to }-80^{\circ} \mathrm{C} \text {. Plasma is thawed before analysis by } \\
\text { Luminex }{ }^{\circledR}, \mathrm{MSD}^{\oplus} \text { or ELISA. }\end{array}$ & $\begin{array}{l}\text { Circulating plasma levels of immune or inflammatory } \\
\text { cytokines and autoantibodies against cytokines, } \\
\text { chemokines, growth factors, adhesion molecules } \\
\text { and injury/death products reflecting the magnitude } \\
\text { of immune cell- and/or tissue activation and/or injury } \\
\text { in vivo. }\end{array}$ \\
\hline
\end{tabular}


Table 2 Stimuli and immune response of TruCulture ${ }^{\oplus}$

\begin{tabular}{lll}
\hline $\begin{array}{l}\text { TruCulture } \\
\text { tube }\end{array}$ & Stimulus & Immune response \\
\hline 1 & $\begin{array}{l}\text { Heat killed Candida } \\
\text { albicans }\end{array}$ & $\begin{array}{l}\text { Whole microbe providing } \\
\text { complex immune response, } \\
\text { including activation of TLR6 }\end{array}$ \\
2 & $\begin{array}{l}\text { Lipopolysaccharide from } \\
\text { E.coli (LPS) }\end{array}$ & $\begin{array}{l}\text { Bacterial endotoxin. Activator } \\
\text { of TLR4. }\end{array}$ \\
3 & Resiquimod R848 & $\begin{array}{l}\text { Synthetic agonist of TLR7 and } \\
\text { TLR8 (both responding to } \\
\text { single-stranded RNA) }\end{array}$ \\
& Polyinosinic:polycytidylic & $\begin{array}{l}\text { Analogue of double-stranded } \\
\text { RNA. Activator of TLR3 }\end{array}$ \\
4 & acid (Poly I:C) & $\begin{array}{l}\text { Allows for assessment of } \\
\text { in vivo activation }\end{array}$ \\
\hline 5 & None (negative control) &
\end{tabular}

the presence of a fungal infection. LPS-EB elicits a strong innate immune response trough TLR4, stimulating an antibacterial immune response. $\mathrm{R} 848$ is a synthetic agonist of TLR7 and TLR8 - both responding to single stranded RNA. PolyI:C is an analogue of doublestranded RNA, and activator of TLR3. Combined, R848 and Polyl:C, thus mimics the presence of viral infection. In addition to the stimulated tubes, one TruCulture ${ }^{\circ}$ tube without stimulus serves as a negative control allowing for assessment of in vivo activation, which may be increased in some patients [24].

Table 2 Showing the stimuli and response of the TruCulture ${ }^{\circ}$ immune function test.

Whole blood is transferred to five different tubes. Four of the tubes are coated with stimulants, mimicking a fungal infection (heat killed Candida albicans), bacterial infection (LPS) and viral infection (Resiquimod R848 and Poly I:C). The fifth tube does not contain stimulant and serves as a negative control. This tube allows for assessment of in vivo activation. The whole blood is incubated for $22 \mathrm{~h}$ at $37^{\circ} \mathrm{C}$ before the supernatant is harvested for analysis of biomarkers, the cells are stabilized with Trizol for analysis of mRNA. TLR: Toll-likereceptors.

Anticoagulated whole blood is transferred to individual TruCulture ${ }^{\circ}$ tubes $60 \mathrm{~min}$ after blood sampling. After 22 $\mathrm{h}$ incubation at $37^{\circ} \mathrm{C}$, the TruCulture ${ }^{\circ}$ supernatant is harvested, aliquoted, and stored at $-80^{\circ} \mathrm{C}$ for later thawing and bulk analysis of soluble immune activation products (cytokines, chemokines, soluble receptors etc.) by Luminex ${ }^{\oplus}$, Meso Scale Discovery ${ }^{\circ} \mathrm{MSD}^{\circ}$ ) or ELISA.

The mRNA in the TruCulture ${ }^{\circ}$ cell pellet is stabilized by Trizol and stored at $-80^{\circ} \mathrm{C}$ for later bulk analysis of mRNA expression level of stimulated immune proteins. The technique applied for mRNA quality control and expression analysis will be commercially available and one that the laboratory is familiar with and applies at the time for mRNA expression analysis e.g. the multiplex assay nCounter
GX Human Immunology Kit (NanoString Technologies) covering 511 human genes (shared among 24 immunology-related gene networks) known to be differentially expressed in immunology.

\section{Clinical data}

Data from electronic health records will be obtained from the PERSIMUNE data repository [31]. These data are automatically generated prospectively as part of routine care and include vital signs, results of routine laboratory analyses of blood for hematology and biochemistry, microbiological examinations, results of imaging studies, pathological examinations of blood and tissue, medication, data on demographics, diagnoses, hospital contacts (outpatient visits and inpatient admissions), surgical procedures and mortality. The PERSIMUNE data warehouse collects data generated from routine patient treatment available for data extraction, as well as additional data from national registries and clinical databases. Patients are linked across data sources using their unique ten-digit civil registration number given to all Danish residents before pseudonymization. All data generated from this study will be stored at the PERSIMUNE data warehouse, approved by the Danish Data Protection Agency.

\section{End-points}

Our primary endpoints are:

1. Infections within 1 year after the transplantation.
a. Blood steam infections
b. CMV infections
c. Pneumonia (virus, bacteria or fungi) requiring hospitalization

2. Graft rejection within 1 year after the transplantation.

a. Rejection defined by pathology

b. Definite or possible rejection that requires medical treatment

Secondary endpoints are:

1. Composite endpoint of infections (viral, bacterial or fungal) or graft rejection within 28 days, 90 days, and 2 years after transplantation

\section{Statistics and power calculation Statistics}

The data from the trial will be analyzed both separately for each patient category using classical statistical analyses and merged across the different patient categories and sampling time-points using computational modelling.

The data will be analyzed by classical statistical analyses i.e. descriptive statistics will be calculated for 
endpoints with summary statistics for continuous variables including $\mathrm{n}$, means with standard deviation and medians with $\mathrm{min} / \mathrm{max}$ or inter quartile ranges and summary statistics for categorical variables including $\mathrm{n}$ and proportions. Differences in continuous variables (including calculated delta-values) within groups between time-points will be analyzed by paired tests ( $\mathrm{t}$-test, Wilcoxon-signed rank test), mixed models or repeated measurements analysis (ANOVA, ANCOVA, Friedman), the latter followed by post hoc pairwise comparisons. Differences across different patient-groups or responses will be analyzed by two-sample $t$ test or Mann-Whitney U test. Differences in categorical values will be analyzed by Chi-square tests or Fishers exact test as appropriate and McNemars test for changes over time.

The predictive value of immunologic variables or categorized immunologic variables for the endpoints will be analyzed by survival statistics including Kaplan-Meier plots and log rank test and Cox proportional hazards models. Furthermore, linear and logistic regression models will be applied to investigate the predictive value of immunologic variables for continuous and categorical endpoints. Analyses may be stratified by underlying disease/baseline patient characteristics, and odds ratios of outcomes among patients with an immunologic variable below or above a certain threshold will be estimated by logistic regression analyses adjusted for relevant covariates. The sensitivity, specificity, positive- and negative predictive value of specific immunologic variables or patterns for outcome will be calculated. $P$-values $<0.05$ will be considered significant.

Furthermore, computational modelling of data applying a bioinformatics approach will be conducted by e.g. unsupervised learning to reveal patterns in the immunologic variables and profile predictive for the endpoints (data mining, clustering and/or Bayesian models, principal component analyses (PCA)).

\section{Statistical power}

The total number of patients planned investigated are $n=630$ SOT recipients. We have performed power calculations to ensure adequate power:

\section{Flow cytometry}

Fernandez-Ruiz et al. [32] have found that a low NKcell count $\left(<0.050 \times 10^{3}\right.$ cells $\left./ \mu \mathrm{L}\right)$ at month one post liver-transplantation was associated with a greater risk of opportunistic infections at month one to six post transplantation. To detect such likely-hood ratio with $\alpha=0.05$ and $\operatorname{power}(\beta)=0.80$ for the incidence rate of 0,09 OI/ 1000 days vs. $0,58 \mathrm{OI} / 1000$ days a total of $n=$ 28 SOT recipients is required.

\section{Plasma biomarkers}

Several studies have reported that plasma sCD30 predicts infectious complications and acute rejection [33, 34 ] in kidney transplant recipients with a $64 \%$ vs. $75 \% 5$ year graft survival in patients with high vs. low sCD30 levels [34]. To detect such likely-hood ratio with $\alpha=$ 0.05 and $\operatorname{power}(\beta)=0.75$, a total of $n=486$ patients is required.

\section{TruCulture ${ }^{\circledast}$}

To our knowledge, TruCulture ${ }^{\circ}$ has not been used to investigate $\mathrm{SOT}$ recipients. In oncologic patients undergoing neoadjuvant radio- and/or chemotherapy before surgery, low IL-12 production in LPS stimulated whole blood cultures predicts increased sepsis-related mortality (58\% vs. 6.6\%) [35]. To detect such likely-hood ratio with $\alpha=0.05$ and power $(\beta)=0.80$, a total of $n=24$ patients is required.

\section{Discussion}

The overall outcome of solid organ transplantation is largely defined by adverse events such as infections and rejections [4-8], and optimal dosage of immunosuppression is of utmost importance. Our general hypothesis is that an improved understanding of the immune function in SOT recipients will lead to an improved management of immunosuppressive therapy, fewer infections and rejections, and improved patient outcomes.

The ability to use functional assays to determine immune function to guide management of immunosuppression has been limited due to time-consuming and expensive assays. However, recently several commercially available functional assays have become available. The ImmuKnow ${ }^{\circ}$ (Cylex, USA) is an FDA approved functional test for cellular immune function. The principle of the test is measuring intracellular adenosine triphosphate (ATP) production in CD4+-cells upon whole blood stimulation with phytohemagglutinin (PHA) [15]. Although the technique is promising, many of the studies conducted with ImmuKnow ${ }^{\circ}$ have limitations including retrospective design, small number of recipients, single measurement and/or low follow-up time, and results so far are conflicting [12-14, 16-23]. One promising randomized controlled study by Ravaioli et al. found that immunosuppression dosed according to results of serial testing with ImmuKnow increased 1-year patient survival and lowered the incidence of infections in liver transplant patients [11]. Another currently available functional test of cellular immune function is the QuantiFERON ${ }^{\circ}$-monitor (QIAGEN). This assay is based on measuring INF- $\gamma$ released after whole blood stimulation with innate (R848) and adaptive (CD3) stimulants [36]. Mian et al. have investigated 137 SOT recipients with the QuantiFERON ${ }^{\circledR}$-monitor 1,3 and 6 month post- 
transplantation and prospectively recorded infections. They found that INF- $\gamma$-levels were lower in patients that developed infections, and that a INF- $\gamma$-level $<10 \mathrm{IU} / \mathrm{mL}$ increased the likelihood of subsequent infection by 2 - to 3-fold [10].

The TruCulture ${ }^{\circ}$ is a novel functional immune assay that will provide complex information about the immune function [24]. TruCulture ${ }^{\circ}$ was developed at the Institut Pasteur, France, with the purpose to be incorporated in the Milieu Intérieur-project, which is a largescale study of 1000 healthy French adults [37]. In the ImmuneMo:SOT study the TruCulture ${ }^{\bullet}$ consists of four carefully chosen stimuli, mimicking fungal, bacterial and viral presence, acting through different TLR pathways. Furthermore, we have chosen 8 cytokines (TNF- $\alpha$, IL$1 \beta$, IL-6, IL-8/CXCL8, IL-10, IL-12p40, IL-17A, IFN- $\gamma$ ) as readout providing a broad and representative image of the immune function. We expect this functional assay to provide much needed information about the global immune function of the SOT-recipients.

This ImmuneMo:SOT study is a non-interventional, observational, prospective study. The primary aim is to generate new knowledge about the immune function in SOT recipients and to link this information to risk of infections and rejections. When combining classical statistics and computational bio-informatic approaches to the data generated, it is expected that the study will be able to generate prediction models that can be used to design a treatment program using personalized medicine. Other ImmuneMo studies including other groups of patients undergoing immune modulating interventions are underway (patients treated with biological treatments, hematopoietic stem cell transplantation recipients, HIV-infected patients, patients with cancer, and patients with severe bacterial infections). Furthermore, a collaboration with $\mathrm{Mi}$ lieu Intérieur will provide the boundaries for the immune function in healthy individuals.

The major strength of this study is the complete immunological profiling that will be conducted in a large number of SOT recipients prior to and after transplantation and across organ types. The immunologic profile is developed in collaboration with the Milieu Intérieur Consortium, Institute Pasteur, Paris, France. This consortium initiated in 2012 a large cross-sectional healthy population-based study, to assess factors underlying immunological variance within the general healthy population. They have enrolled 1000 healthy WesternEuropean adults; 500 women and 500 men, consisting of 100 study-participants of each sex in each of 5 agegroups from 20 to $29,30-39,40-49,50-59$ and 60-69 year. The study-participants was (among others) assessed with a deep immunological and genetic investigation, including the use of TruCulture ${ }^{\bullet}$ [25]. This provides us a unique opportunity to compare the immune function of our study-participants to healthy controls.

Another strength, and a precondition for the feasibility of this study, is that all Danish residents are provided with a unique 10-digit personal identification number by the The Civil Registration System. This number is registered at all contacts with the health care system and allows for accurate linkage with the clinical information from the PERSIMUNE data repository.

A weakness of the study is the single-center design. The patients recruited at one geographical locality and may not be representative for patients from other geographical areas. However, as Rigshospitalet is the largest center for transplantation in Denmark and the only center in Denmark for liver and lung transplantation, it does provide a unique opportunity to perform this study and it is realistic to include patients as described.

In conclusion, there is a need for an improved understanding of immune function in SOT recipients to target the constant challenge of balancing the immunosuppression to avoid both infections and rejections.

This project has brought together the competences of many experts, including expertise within infectious diseases, immunology, and transplantation medicine. We hypothesize that the full immunologic profile, consisting of both immune phenotyping, circulating biomarkers and immune function, will provide important knowledge about the effect of organ transplantation and immunosuppression on the recipients' immune function. And that this knowledge can be used to identify SOT recipients at excess risk of infections and rejections.

If the study is successful, the study group will use the results to design a randomized clinical trial to test personalized immunosuppressive regimes according to the recipient's individual immunological profile. In the future both initial immunosuppression and monitoring of immunosuppression might be based on the personal immune profile as proposed in this study.

\section{Abbreviations \\ E.coli: Escherichia coli; ELISA: Enzyme linked immunosorbent assay; HKCA: Heat killed Candida albicans; LPS: Lipopolysaccharide; mRNA: Messenger RNA; MSD: Meso Scale Discovery; PERSIMUNE: Centre of Excellence for Personalised Medicine of Infectious Complications in Immune Deficiency; poly I:C: Polyinosinic:polycytodylic acid; SOT: Solid organ transplantation; TLR: Toll like receptors}

\section{Acknowledgements}

Not applicable.

\section{Authors' contributions}

CD, SO, OR, AR, SSS, FG, MP, JDL, SD conceptualized the study. SO, SD obtained ethical approval. SO, JDL, SD obtained funding. CD, SO, SD drafted the manuscript for publication. All authors read and approved the final manuscript. 


\section{Funding}

The trial is funded by The Novo Nordisk Foundation (NNF180C0030978), Independent Research Fund Denmark (8020-00023B), The Augustinus Foundation and The Danish National Research Foundation (DNRF 126). We have applied, and will continue applying, external funding to cover remaining expenses.

The funders had no role in study design and will have no role in data collection and analysis, decision to publish, or preparation of manuscript. The primary investigator, co-investigators and/or sponsors are not financially attached to private enterprises, foundations etc. Patients are not paid for their participation in the trial.

\section{Availability of data and materials}

Use of data will be confined to the study group, but potential collaborators or request for data and/or other materials such as consent forms, information to participants and data-management documentation (in Danish) can be submitted at sdn@dadlnet.dk.

\section{Ethics approval and consent to participate}

The only risk associated with participation is that related to blood puncture There are no benefits associated with participation for the individual participant, but it is considered that the risk associated with participation is low compared to the potentially valuable information obtained. The participation is strictly voluntary, participants are not paid for participation. Participants can withdraw from the study at any given time, without explanation. The nurse will obtain informed consent or assent from potential trial participants upon verbal and written information. The consent includes collection and use of participant data and storage of biologic specimens for ancillary studies.

The study is conducted in accordance with the Helsinki 2 declaration and has been approved by the Danish Data Protection Agency (RH-2016-47) and the Ethical Committee $(\mathrm{H}-17024315)$.

Collection and storage of data in the PERSIMUNE data repository has been approved by the Danish Data Protection Agency (RH-2015-04, I-Suite 03605) and the Danish National board of Health (jr.nr. 3-3013-1060/1).

The trial is registered at clinicaltrials.gov (NCT03847285). The trial registration will be continuously updated with relevant protocol modifications if any.

\section{Consent for publication}

Not applicable.

\section{Competing interests}

SDN: Unrestricted research grants from Novo Nordisk Foundation, Lundbeck Foundation, Augustinus Foundation, Rigshospitalet Research Council. Travelling grants from Gilead, MSD, BMS, and GSKNiiV. Advisory board activity for Gilead and GSKNiiV. SDN is also a member of BMC Infectious Diseases Editorial Board.

FG: Unrestricted research grants from the Novo Nordisk Foundation, Erik and Susanne Olesens Foundation, advisory board participation Pfizer, Pharmacosmos and Bayer. Unpaid scientific advisor CARMAT, Corvia. Speakers fee Abbott, Orion, Novartis.

MP: Research grants from Roche, PulmonX and BTG, Travelling grants from Novartis, Boeringer-Ingelheim, BTG, Therakos and MSD. Lecture MSD, BTG, and Novartis.

CD, OR, AR, SSS, JDL, SRO: no competing interests.

\section{Author details}

${ }^{1}$ Viro-immunology Research Unit, Department of Infectious Diseases, Rigshospitalet, University of Copenhagen, Copenhagen, Denmark. ${ }^{2}$ Department of Nephrology, Rigshospitalet, University of Copenhagen, Copenhagen, Denmark. ${ }^{3}$ Department of Surgical Gastroenterology and Transplantation, Rigshospitalet, University of Copenhagen, Copenhagen, Denmark. ${ }^{4}$ Department of Cardiology, Section for Lung Transplantation, Rigshospitalet, University of Copenhagen, Copenhagen, Denmark. ${ }^{5}$ Department of Cardiology, Rigshospitalet, University of Copenhagen, Copenhagen, Denmark. ${ }^{6}$ Department of Infectious Diseases and CHIP, Centre of Excellence for Health, Immunity and Infections and PERSIMUNE, Centre of Excellence for Personalized Medicine of Infectious Complications in Immune Deficiency, Rigshospitalet, University of Copenhagen, Copenhagen, Denmark. ${ }^{7}$ Department of Clinical Immunology, Rigshospitalet, University of Copenhagen, Copenhagen, Denmark.
Received: 4 April 2019 Accepted: 19 June 2019

Published online: 03 July 2019

\section{References}

1. AnnualScandiatransplantdatareport2017.pdf [Internet]. [cited 2019 Jan 4]. Available from: http://www.scandiatransplant.org/resources/ AnnualScandiatransplantdatareport2017.pdf

2. Koller M, Stampf S, Rick J, Branca S, Bianco S, Rossi S, et al. Swiss Transplant Cohort Study report (May 2008-December 2017). :78.

3. Wareham NE, Da Cunha-Bang C, Borges ÁH, Ekenberg C, Gerstoft J, Gustafsson F, et al. Classification of death causes after transplantation (CLASS): evaluation of methodology and initial results. Medicine (Baltimore). 2018:97:e11564

4. Snydman DR. Epidemiology of infections after solid-organ transplantation. Clin Infect Dis. 2001:33:S5-8.

5. Shaked A, Ghobrial RM, Merion RM, Shearon TH, Emond JC, Fair JH, et al. Incidence and severity of acute cellular rejection in recipients undergoing adult living donor or deceased donor liver transplantation. Am J Transplant. 2009:9:301-8.

6. Cippà PE, Schiesser M, Ekberg H, van Gelder T, Mueller NJ, Cao CA, et al. Risk stratification for rejection and infection after kidney transplantation. Clin J Am Soc Nephrol. 2015:10:2213-20.

7. Gauthier JM, Li W, Hsiao H-M, Takahashi T, Arefanian S, Krupnick AS, et al. Mechanisms of graft rejection and immune regulation after lung transplant. Ann Am Thorac Soc. 2017;14:S216-9.

8. Felkel TO, Smith AL, Reichenspurner HC, LaFleur B, Lutz JF, Kanter KR, et al. Survival and incidence of acute rejection in heart transplant recipients undergoing successful withdrawal from steroid therapy. J Heart Lung Transplant. 2002;21:530-9.

9. Dendle C, Mulley WR, Holdsworth S. Can immune biomarkers predict infections in solid organ transplant recipients? A review of current evidence. Transplantation Reviews [Internet] 2018 [cited 2018 Dec 21]; Available from: https://linkinghub.elsevier.com/retrieve/pii/S0955470X18300648.

10. Mian $M$, Natori Y, Ferreira V, Selzner N, Husain $S$, Singer L, et al. Evaluation of a novel global immunity assay to predict infection in organ transplant recipients. Clin Infect Dis. 2018;66:1392-7.

11. Ravaioli M, Neri F, Lazzarotto T, Bertuzzo VR, Gioia PD, Stacchini G, et al. Immunosuppression modifications based on an immune response assay: results of a randomized, controlled trial. Transplantation. 2015;99:1625-32.

12. Qu W, Zhu Z-J, Sun L-Y, Wei L, Liu Y, Zeng Z-G. Correlation between survival interval and CD4+ T-cell intracellular ATP levels in liver transplant recipients. Transplant Proc. 2017:49:316-21.

13. Takahashi M, Ohsumi A, Ohata K, Kondo T, Motoyama H, Hijiya K, et al. Immune function monitoring in lung transplantation using adenosine triphosphate production: time trends and relationship to postoperative infection. Surg Today. 2017:47:762-9.

14. Sood S, Testro AG. Immune monitoring post liver transplant. World J Transplant. 2014:4:30-9.

15. Kowalski R, Post D, Schneider MC, Britz J, Thomas J, Deierhoi M, et al. Immune cell function testing: an adjunct to therapeutic drug monitoring in transplant patient management. Clin Transpl. 2003;17:77-88.

16. Piloni D, Magni S, Oggionni T, Benazzo A, Stella G, Scudeller L, et al. Clinical utility of CD4+ function assessment (ViraCor-IBT Immuknow test) in lung recipients. Transpl Immunol. 2016;37:35-9.

17. Nishikawa K, Mizuno S, Masui S, Kanda H, Yamada Y, Arima K, et al. Usefulness of monitoring cell-mediated immunity for predicting Postkidney transplantation viral infection. Transplant Proc. 2014;46:552-5.

18. Bhorade SM, Janata K, Vigneswaran WT, Alex CG, Garrity ER. Cylex Immuknow assay levels are lower in lung transplant recipients with infection. J Heart Lung Transplant. 2008;27:990-4.

19. Gautam A, Fischer SA, Yango AF, Gohh RY, Morrissey PE, Monaco AP. Cell mediated immunity (CMI) and post transplant viral infections - role of a functional immune assay to titrate immunosuppression. Int Immunopharmacol. 2006;6:2023-6.

20. Gupta S, Mitchell JD, Markham DW, Mammen PPA, Patel PC, Kaiser PA, et al. Utility of the Cylex assay in cardiac transplant recipients. J Heart Lung Transplant. 2008;27:817-22.

21. Huskey J, Gralla J, Wiseman AC. Single time point immune function assay (ImmuKnowTM) testing does not aid in the prediction of future opportunistic infections or acute rejection. Clin J Am Soc Nephrol. 2011;6:423-9. 
22. Chiereghin A, Petrisli E, Ravaioli M, Morelli MC, Turello G, Squarzoni D, et al. Infectious agents after liver transplant: etiology, timeline and patients' cellmediated immunity responses. Med Microbiol Immunol. 2017;206:63-71.

23. Pérez-Jacoiste Asín MA, Fernández-Ruiz M, López-Medrano F, Aquilino C, González E, Ruiz-Merlo T, et al. Monitoring of intracellular adenosine triphosphate in CD4(+) T cells to predict the occurrence of cytomegalovirus disease in kidney transplant recipients. Transpl Int. 2016;29:1094-105.

24. Duffy D, Rouilly V, Libri V, Hasan M, Beitz B, David M, et al. Functional analysis via standardized whole-blood stimulation systems defines the boundaries of a healthy immune response to complex stimuli. Immunity. 2014:40:436-50

25. Thomas S, Rouilly V, Patin E, Alanio C, Dubois A, Delval C, et al. The milieu Intérieur study - an integrative approach for study of human immunological variance. Clin Immunol. 2015;157:277-93.

26. Hasan M, Beitz B, Rouilly V, Libri V, Urrutia A, Duffy D, et al. Semi-automated and standardized cytometric procedures for multi-panel and multi-parametric whole blood immunophenotyping. Clin Immunol. 2015;157:261-76.

27. Chen X, Hasan M, Libri V, Urrutia A, Beitz B, Rouilly V, et al. Automated flow cytometric analysis across large numbers of samples and cell types. Clin Immunol. 2015;157:249-60.

28. Urrutia A, Duffy D, Rouilly V, Posseme C, Djebali R, llanes G, et al. Standardized whole-blood transcriptional profiling enables the deconvolution of complex induced immune responses. Cell Rep. 2016;16: 2777-91.

29. Pasteur research pasteur fr-Institut. The Healthy Human Global Project • Research [Internet]. Research. [cited 2019 Feb 5]. Available from: https:// research.pasteur.fr/en/program_project/the-healthy-human-global-project/.

30. Duffy D, Rouilly V, Braudeau C, Corbière V, Djebali R, Ungeheuer M-N, et al. Standardized whole blood stimulation improves immunomonitoring of induced immune responses in multi-center study. Clin Immunol. 2017;183: 325-35.

31. Persimune $>$ Home [Internet]. [cited 2019 Feb 5]. Available from: http:// www.persimune.dk/.

32. Fernández-Ruiz M, Silva JT, López-Medrano F, Allende LM, San Juan R, Cambra F, et al. Post-transplant monitoring of NK cell counts as a simple approach to predict the occurrence of opportunistic infection in liver transplant recipients. Transpl Infect Dis. 2016;18:552-65.

33. Fernández-Ruiz M, Kumar D, Humar A. Clinical immune-monitoring strategies for predicting infection risk in solid organ transplantation. Clinical \& Translational Immunology. 2014;3:e12.

34. Süsal C, Pelzl S, Döhler B, Opelz G. Identification of highly responsive kidney transplant recipients using Pretransplant soluble CD30. JASN. 2002;13:1650-6.

35. Novotny AR, Emmanuel K, Ulm K, Bartels $H$, Siewert J-R, Weighardt $H$, et al Blood interleukin 12 as preoperative predictor of fatal postoperative sepsis after neoadjuvant radiochemotherapy. Br J Surg. 2006;93:1283-9.

36. QuantiFERON Monitor - QuantiFERON [Internet]. [cited 2019 Feb 20]. Available from: https://www.quantiferon.com/products/quantiferonmonitor/.

37. Milieu Intérieur | Vers une médecine personnalisée [Internet]. [cited 2019 Feb 22]. Available from: http://www.milieuinterieur.fr/en.

\section{Publisher's Note}

Springer Nature remains neutral with regard to jurisdictional claims in published maps and institutional affiliations.

\section{Ready to submit your research? Choose BMC and benefit from:}

- fast, convenient online submission

- thorough peer review by experienced researchers in your field

- rapid publication on acceptance

- support for research data, including large and complex data types

- gold Open Access which fosters wider collaboration and increased citations

- maximum visibility for your research: over $100 \mathrm{M}$ website views per year

At BMC, research is always in progress.

Learn more biomedcentral.com/submissions 